\title{
Smart ANN Controller for TCR/TSC Devices used in Power System Applications
}

\author{
Shubham Shukla ${ }^{1}$, Imran Khan ${ }^{2}$, Mohd. Asif $\mathrm{Ali}^{3}$ \\ ${ }^{1}$ Azad Institute of Engineering and Technology, India, sshubham227@gmail.com \\ ${ }^{2}$ Azad Institute of Engineering and Technology, India, pe.imran@ gmail.com \\ ${ }^{3}$ Azad Institute of Engineering and Technology, India, asifaliec@ gmail.com
}

\begin{abstract}
Reactive power compensation and voltage regulation using thyristor controlled reactor (TCR) and thyristor-switched capacitor (TSC) circuit is performed. The goal is the minimization of the rms and THD values due to dynamic voltage supply by controlling the firing angle value of the TCR /TSC branch using smart artificial neural network (ANN) controller. Some changes in the conventional control architecture of the Conventional TCR/TSC based SVC compensator is made to achieve it. We have shown that substitution of the ANN controller by a advanced controlling forces of the thyristor-firing angle for improving the power factor and the total harmonic distortion of the line voltage and current (THD). These changes are tested on effectiveness with fluctuating linear loads. For simulation purposes, TCR/TSC models, and loads, represented respectively by RLC circuits are considered. For several illustrative cases, an optimized ANN controller design is applied in each half-cycle of the voltage source, and optimum values of firing angles are obtained satisfying condition of minimum r.m.s value of the line supplies. PF and THD is calculated in the considered cases to show the performance of the TCR/TSC compensator.
\end{abstract}

Key words: SVC, Power System, TCR, TSC.

\section{INTRODUCTION}

In the control of electrical power systems, systems and procedures are used to compensate dynamically the detrimental effects of non-linear loads. The compensation process should be resulted without important alteration of the source signals quality. Some benefits are expected using compensation: losses reduction in the distribution lines, harmonic content, and power factor improvement. The dynamic behavior of industrial loads requires the use of compensator that can be adapted to load changes. Unfortunately, the techniques frequently used for compensation are based on circuit controllers that alter the waveform of the signals subject to the control. Such is the case of the static compensator [2], which must perform harmonics cancellation, reactive power compensation, power factor correction, and energy saving. Although the static compensator is commonly used and studied under sinusoidal voltage conditions, waveforms corresponding to the controlled current present high harmonic content. This paper focuses on the thyristor-controlled reactor (TCR) [3].
TCR consists of controlling the current in the reactor $\mathrm{L}$ from a maximum (thyristor valve $\mathrm{T}$ closed) to zero (thyristor valve $\mathrm{T}$ open) by the method of firing delay angle control. The fixed capacitor (FC) and the TCR constitute a basic var generator arrangement (FC-TCR). The constant capacitive var generation of $\mathrm{C}$ is opposed by the variable var absorption of the TCR. Calculation of the firing angle can be made in the time domain [4] or in the frequency domain $[5,6]$, using different approaches. Assuming the supply voltage is sinusoidal, calculation of the tiring angle is obtained with minimum complexity [1], [7]. However, the modification of the TCR firing angle, increasing from limits $\mathrm{a}=0$ to $\mathrm{a}=\mathrm{d} 2$, produces increasing distortion of the current in the TCR branch, and consequently that of the line current. It increases the rms value of the line current and the THD, and deteriorates the power factor. This situation is still more degraded in the usual situation where the voltage signal is not purely sinusoidal. In this work, the goal is the minimization of the rms and THD values of the line current, controlling the firing angle value of the TCR branch. Some changes in the conventional architecture of the TCR compensator were necessary to achieve it [8].

\section{RELATED WORK}

Kunal Gupta et. al. (2017) [14], Transient stability control plays an important role in ensure the stable operation of power systems in the experience of large disturbances and faults, and is thus an important area of research. This paper investigates relationship of SVC, STATCOM and UPFC performance for the transient stability improvement of the power system. The enhancement of transient stability of the power system, using SVC (Static VAR Compensator), STATCOM (Static Synchronous Compensator) and UPFC (Unified Power Flow Controller) which is an effective FACTS (Flexible AC Transmission System) device able of controlling the active and reactive power flows in a transmission line by controlling appropriately parameters. Simulations are carried out in Mat lab/ Simulink environment [9]. The presentation of SVC, STATCOM\& UPFC is compared from each other. So for the improvement of transient stability STATCOM is superior to SVC. The simulation results demonstrate the value and robustness of the proposed STATCOM, UPFC\& SVC on transient stability improvement of the system.

The comparison of the SVC, STATCOM and UPFC, controller applications. The detailed models of the SVC, STATCOM, and UPFC were implemented and tested in the EMT (electro-magnetic transients). The models are relevant 
for transient stability analysis, and cover broader range of frequency oscillations and voltage control. The STATCOM give better performance than SVC for reactive power, voltages and loading capacity. For STATCOM reactive power compensated from 13.11 MVAR (SVC) to 15.83 MVAR (STATCOM) and voltage injected from $464.4 \mathrm{kv}$ (SVC) to $469.8 \mathrm{kv}$ (STATCOM) at bus 2.another relation with UPFC give better-quality performance than STATCOM for reactive power, voltages and loading capacity. For UPFC reactive power compensated from 15.83 MVAR (STATCOM) to 22.26 MVAR (UPFC) and voltage injected from $469.8 \mathrm{kv}$ (STATCOM) to 471.1 (UPFC) kv at bus 2 and table no. $5.2 \& 5.3$ [13].

Mai Mahmoud Eladany et. al. (2018) [15] It is of crucial importance to obviate power system damage and cascading failures that may cause a full or partial blackout when the system is exposed to severe contingencies [10]. Flexible alternating current transmission system (FACTS) devices have been harnessed for solving several power system problems including transient stability. Ever since, to emphasize the effectiveness of the FACTS technology, the number and allocation of these devices must be selected properly. So, a novel algorithm is proposed in this paper to determine the best least number (BLN) and allocation of the thyristor-controlled series capacitor (TCSC) with a goal of improving the transient stability in an optimal manner. A combination of the catastrophe theory (CT) and the multiobjective particle swarm optimization (MOPSO) method in addition to a clustering technique is used to structure the proposed algorithm. The CT is used to assess the transient stability and calculate the critical clearing time (CCT). MOPSO is applied to compromise between maximizing the CCT and minimizing the cost of TCSCs as two contradictory objective functions. The clustering technique is designed to provide the BLN of TCSC devices. Accordingly, at least investment the proposed algorithm satisfies an increase of the stability margin by increasing the value of CCT for each generator and improves the location of operating points in the CT's stability region. Simulation of the proposed algorithm application to New England 39bus power system is presented to verify the algorithm effectiveness. The results confirm the feasibility of this algorithm and are validated in comparison with those obtained through time-domain simulation.

A. Girdenis et. al., (2019) [16] Power systems including a collection of dynamic interconnected subsystems and devices. The control systems must have the capability of coordinating all sub-controllers under diverse operating conditions and limits. In the last decades, to cope with the increasing need for electric power, more and more FACTS devices are employed to enhance the transmission capability of the existing transmission system. As a result, the stability margin of power systems has decreased as the complexity of power systems has increased dramatically. This paper introduces the design and analysis of a nonlinear variablegain ANFIS controller for a flexible ac transmission systems (FACTS) device such as the unified power flow controller (UPFC) to improve the transient stability efficiency of power systems [11]. In ANFIS training, the radius vector of clusters has a high effect on the efficiency of ANFIS. For his reason in this paper, the bees algorithm is suggested in finding the optimum radius vector. Computer simulation results confirm the superior performance of this hybrid controller.

In this paper, we proposed a nonlinear variable-gain controller for the UPFC. Create of controller parameters is dealt with in great detail for enhancing the stability performance of a power system by a powerful type of the optimized TS ANFIS control structure. The new fuzzylogic-based control scheme provide a widespread fluctuant of the control gains, depending on the operating situations of the power system and, therefore, a high performance in comparison with the linear PI controllers applied in the UPFC. In the proposed TS [12] ANFIS-control scheme, the rule consequent could be both a linear and a nonlinear function of input sets variable, and, therefore, a superb nonlinear variable- gain controller may be realized. The performance of the UPFC with the proposed optimized TS ANFIS-control scheme is tested vis-à-vis the classical PI control to support its superior performance in respect of transient stability improvement in a single-machine power system case. This controller or proposed method is found to be very powerful to error location and supply high transient stability performance enhancement over a wide range of operating fuzzy situations. Both inter-area and local modals of power system fluctuant are damped much rapidly by this proposed controller compared with the classical PI controller. Furthermore, the error clearing time is enhanced noticeably with this intelligent controller.

\section{SIMULATION MODEL}

An SVC voltage regulation at $6000-\mathrm{MVA} 735-\mathrm{kV}$ system is developed to demonstrate using ANN controller. The SVC has a $735 \mathrm{kV} / 16-\mathrm{kV}$ 333-MVA transformer, a 109Mvar thyristor-controlled reactor (TCR) and three 94 MVAR thyristor-switched capacitor (TSC 1,2 and 3) at secondary side. ANN based firing control of TSCs supports a variation of reactive power upto 282 MVAR capacitive at steps wise addition of 94 MVAR one by one by each TSC and the control of phase at TCR supports a variation from upto 109 MVAR inductive. In this way the reactance of the at transformer side is adjusted by SVC resultant susceptance from $-1.04 \mathrm{pu} / 100 \mathrm{MVA}$ at fully inductive reactance mode to $+3.23 \mathrm{pu} / 100 \mathrm{Mvar}$ at fully capacitive mode. The SVC gets the primary voltage as feedback and modulates the pulses of thyristors to provide a susceptance as per the desired reference value given to the voltage regulator. 


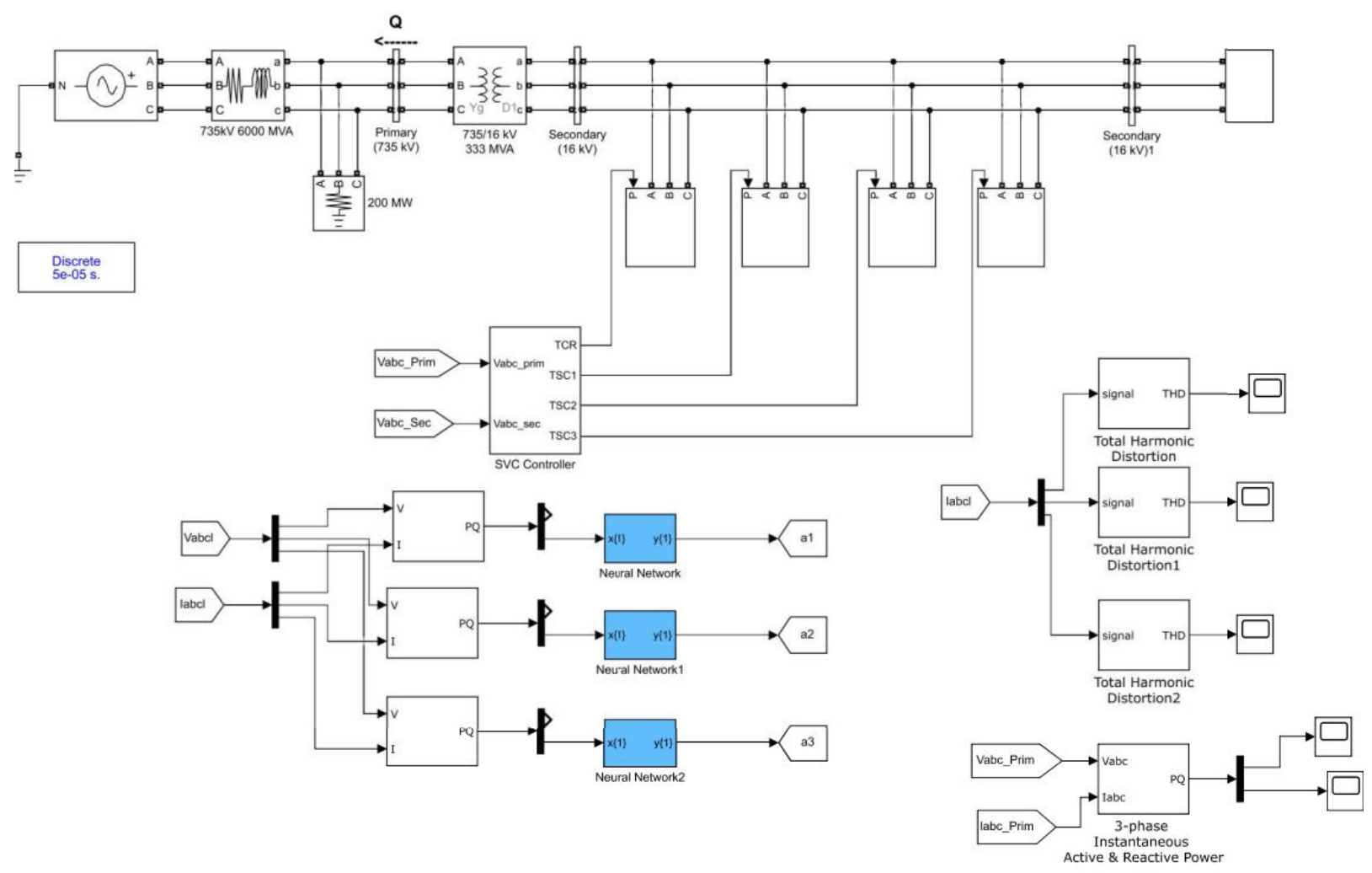

Figure 1: ANN controller based TCR and TSC based SVC regulated power system

The TCR and TSC are shown as a subsystem-block (figure 1) they are actually representing delta connected three-phase bank. Due to delta connection the $3^{\text {rd }}, 9^{\text {th }} \ldots$ harmonics are trapped thus reducing power system harmonic injection is reduced. The three phase system is described by inductive equivalent source of 6000 MVA rating and a 200-MW load. The voltage source supply is controllable by ANN and it is a programmable source to observe the SVC performance dynamic conditions due to fluctuation in source voltage. The voltage source output sequence of voltage varies in stepwise programmed variations.

\section{SYSTEM PERFORMANCE}

The simulation is described in terms of scope waveforms for dynamic behavior of the SVC model. Since the incoming voltage is varying hence voltage regulation mode by ANN controller is applied and for the controller the reference voltage Vref $=1.0$ pu. The voltage droop of the ANN controller is taken at $0.01 \mathrm{pu} / 100 \mathrm{VA}$. Therefore when the SVC operating point undergoes through switching of TCR and TSC from capacitive reactance +300 Mvar to inductive reactance -100 Mvar association the SVC voltage supply fully lies in $1-0.03=0.97 \& 1+0.01=1.01 \mathrm{in} \mathrm{pu}$.

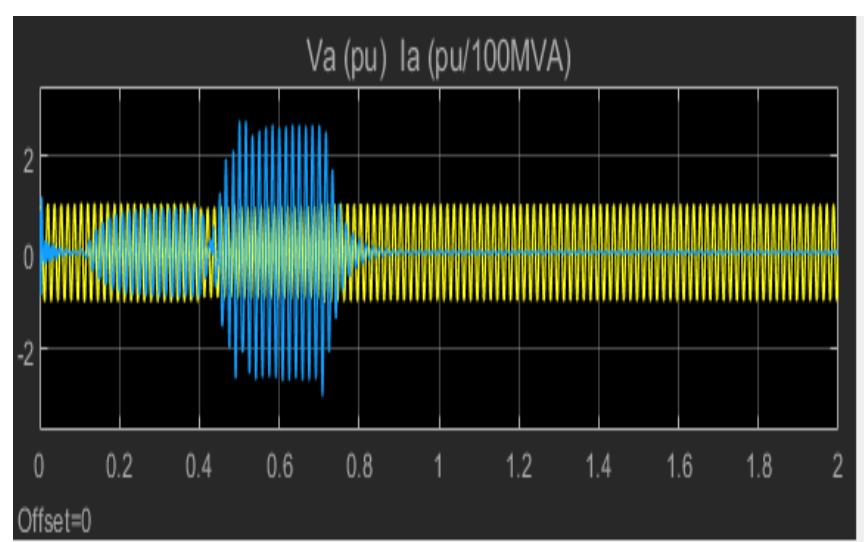

Figure 2: Voltage source dynamics due to fluctuation.

Initially voltage supply is taken at set at 1.004 pu that results in approx. $1.0 \mathrm{pu}$ voltage at SVC terminals when the SVC is out of service see figure 2. Since Vref is desired to be at 1.0 $\mathrm{pu}$, the SVC is inactive and produces zero current to its output. This operating conditions are only maintained by using the TSC1 and TCR at this situation is acting in the full conduction mode at firing angle alpha $=96^{\circ}$. On the start of time $\mathrm{T}=0.1$ seconds the voltage abruptly raised to $1.025 \mathrm{pu}$. The SVC starts to absorb the reactive power (Q=-94 Mvar) to degrade the voltage at lower value as previously to 1.01 pu. The transient are observed to be settled down within 135 msec approximately. In this time zone the TSCs are presently inactive and the TCR is only responsible for regulation and works in full conduction mode. 


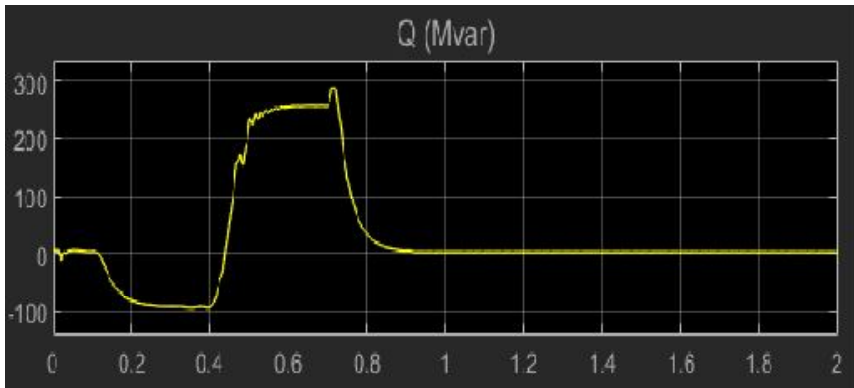

Figure 3: Controlled reactive power generation by TCR and TSC to compensate voltage fluctuation

On the instant time $\mathrm{T}$ after $0.4 \mathrm{sec}$ the source voltage is suddenly lowered to $0.93 \mathrm{pu}$. The SVC to compensate the decay generates 256 Mvar of reactive power and the voltage settles to level of $0.974 \mathrm{pu}$. To perform this compensation of voltage dip all the TSCs become active and the TCR absorbs approximately $40 \%$ of its nominal reactive power at switches the firing angle from alpha from 94 degree to 120 degrees shows in figure 3. In this zone of regulation of voltage the trace of signals of TSCs are sequentially switched on and off. As a TSC is switched on the TCR alpha angle changes suddenly from 180 degrees (no conduction) to 90 degrees (full conduction). Finally as the voltage the voltage reaches back to $1.0 \mathrm{pu}$ and the fluctuations are ended up the SVC reactive performance is of and output reaches to zero.

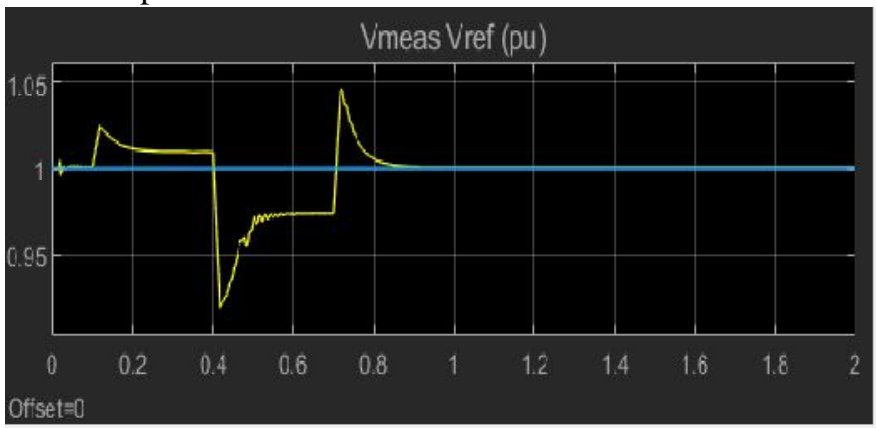

Figure 4: Voltage regulation by the ANN controller Whenever TSC switch goes to off condition its capacitor remains charged. Due to this the voltage at thyristor conducting the positive current signal is fired at maximum negative TSC voltage as the voltage across whole switch is reaching at the minimum value shows in figure 4 . If the ANN controller is not properly tuned then firing pulse is not slightly delayed under dynamic conditions and it causes very-very high flow of current through the TSC switches.

\section{CONCLUSION}

SVC ANN controller block should not give false firing hence A the pulses synchronized to sample are very crucial. Otherwise such false firing time when voltage is maximum positive as TSC is blocked produces high thyristor current more than 5 times the peak current rating and also as thyristor is block the voltage across it reaches 3.8 times the normal peak value of voltage. Such over-currents and overvoltages at thyristor of TSC are protected using arresters devices.

\section{REFERENCES}

[1] T. J. E. Miller, "Reactive Power Control in Electric Systems", John Wiley \& Sons, New York 1982.

[2] S. Y. Lee, S. Bhattacharya, T. Lejonberg, A. Hammad and S. Lefebvre, "Detailed Modeling of Static Var Compensators Using the Electromagnetic Transients Program (EMTP)", IEEE Trans. on Power Delivery, Vol. 7, No. 2, pp. 836-47, April 1992.

https://doi.org/10.1109/61.127088

[3] G. G. Karady, 'Continuous Regulation of Capacitive Reactive Power", IEEE Trans. on Power Delivery, Vol. 7, No. 3, pp. 1466-73, July 1992.

[4] A. Gomez, F. Gonzllez, C. Izquierdo, T. Gonzllez and F. Pozo, "Microprocessor-Based control of an SVC for optimal load Compensation", IEEE Trans. on Power Delivery, vol. 7, no. 2, pp. 706-712, April 1992.

[5] J. C. Montafio, J. Gutierrez, A. Lopez and M. Castilla, "Effects of Voltage Waveform Distortion in TCR-Type Compensators", IEEE Trans. on Industrial Electronics, vol. 40, no. 1, pp. 373-381. June 1993.

[6] Anurag, R. Sharma, " Load Forecasting by using ANFIS", International Journal of Research and Development in Applied Science and Engineering, Volume 20, Issue 1, 2020.

[7] R. Sharma, Anurag, " Load Forecasting using ANFIS A Review", International Journal of Research and Development in Applied Science and Engineering, Volume 20, Issue 1, 2020.

[8] R. Sharma, Anurag, " Detect Skin Defects by Modern Image Segmentation Approach, Volume 20, Issue 1, 2020.

[9] Anurag, R. Sharma, " Modern Trends on Image Segmentation for Data Analysis- A Review", International Journal of Research and Development in Applied Science and Engineering, Volume 20, Issue 1, 2020.

[10] J. Gutitrrez, J. C. Montatio, A. Lopez and M. Castilla,"Effects of harmonic distortion of the supply voltage on the optimum performance of a thyristorcontrolled reactor-type compensator". IEE Proceedings Science, Measurement and Technology, Vol. 141, no. I, pp.15-19. January 1994.

https://doi.org/10.1049/ip-smt:19949422

[11] N. G. Hingorani and L. Gyugyi, "Understanding Facts, Concepts and Technology of Flexible AC Transmission Systems", IEEE Press, New York. 2000.

[12] Young Soo Jang et. al., "Development of the costeffective, miniaturized vein imaging system with enhanced noise reduction", International Journal of Advanced Trends in Computer Science and Engineering, Volume 8, No.6, November - December 2019.

https://doi.org/10.30534/ijatcse/2019/80862019

[13] Irma T. Plata1, et. al., "Development and Testing of Embedded System for Smart Detection and Recognition of Witches' Broom Disease on Cassava Plants using Enhanced Viola-Jones and Template Matching Algorithm", International Journal of Advanced Trends in Computer Science and Engineering, Volume 8, No.6, Volume 8, No.5, September - October 2019. 